J. Fish. Sci. Tech. 5(2), 122 126, 2002

\title{
Compensatory Growth in Juvenile Olive Flounder (Paralichthys olivaceus) in the Spring
}

\author{
Sung Hwoan Cho* and Jong Kwan Lee \\ Uljin Marine Hatchery, National Fisheries Research and Development Institute, Uljin, \\ Kyungbook 767-863, Korea
}

(Received February 2002, Accepted June 2002)

\begin{abstract}
A feeding trial was conducted to determine compensatory growth of juvenile olive flounder in the spring. Five treatments of fish with 3 replicates were prepared: the control group fish (C) fed twice daily for 8 weeks, the S1, S2, S3 and S4 fish fed for 7, 6, 5 and 4 weeks after $1,2,3$ and 4 weeks of starvation, respectively. Survival of olive flounder was not significantly different among treatments. Weight gain of flounder in S2 was significantly $(P<0.05)$ higher than that of fish in S3 or S4, but not significantly different from that of fish in C or S1. The poorest weight gain was observed in fish of S4 treatment. Specific growth rate (SGR) for flounder in S2 was significantly $(\mathrm{P}<0.05)$ higher than that for fish in $\mathrm{C}$ or $\mathrm{S} 4$, but not significantly different from that of fish in S1 or S3. Feed intake $(\mathrm{g} / \mathrm{fish})$ was proportional to duration of days of feeding except for flounder in S2, but not significantly different among $\mathrm{C}, \mathrm{S} 1$ or S2. Feed efficiency ratio (FER) and protein efficiency ratio (PER) for flounder in $\mathrm{S} 2$ were significantly $(\mathrm{P}<0.05)$ higher than for fish in $\mathrm{C}$, but not significantly different from those for fish in S1, S3 or S4. Hepatosomatic index (HSI) and condition factor (CF) for flounder in S1, S3 and S4 were not significantly different from those for fish in C, but significantly $(\mathrm{P}<0.05)$ lower than S2 except for $\mathrm{CF}$ in $\mathrm{S} 1$ at the end of the experiment. Proximate composition of the whole body of flounder was not significantly different among treatments. In considering results of the experiment, juvenile olive flounder achieved compensatory growth when properly fed after starved up to 2 weeks in the spring. Compensatory growth of fish was supported by improvement in SGR, FER and PER in fish starved.
\end{abstract}

Key words: Olive flounder, Paralichthys olivaceus, Compensatory growth, SGR, FER

\section{Introduction}

Compensatory growth in fish, a rapid growth or faster than normal growth rate resulted from followed refeeding of fish after starvation during a certain period of time, has been observed in some of coldwater fish, such as Arctic charr Salvelinus alpinus (Miglavs and Jobling, 1989), rainbow trout Oncorhynchus mykiss (Dobson and Holmes, 1984; Jobling and Koskela, 1996), sockeye salmon Oncorhynchus nerka (Bilton and Robins, 1973) and coho salmon Oncorhynchus kisutch (Damsgaard and Dill, 1998) as well as warmwater fish, such as channel catfish Ictalurus punctatus (Gaylord and Gatlin,

*Corresponding author: chosunh @yahoo.com
2000; 2001), hybrid tilapia, Oreochromis mossambicus $\times O$. niloticus (Wang et al., 2000) and gibel carp Carassius auratus gibelio (Qian et al., 2000; Xie et al., 2001).

Fish achieving compensatory growth would usually eat more feed than normal fish shortly after starvation to compensate the defective growth while starved. However, poor survival and growth of fish starved over critical period of time was observed in most cases. Recently, the effective dietary composition to maximize compensatory growth of channel catfish after starvation was also reported (Gaylord and Gatlin, 2001). Achieving compensatory growth in fish after starvation has the several positive potential for aquaculture in terms of saving personnel time, probably producing less pollution during starvation and improving fish-feeding activity, and it 
can eventually reduce fish production cost. Therefore, many fish farmers are probably very interested in compensatory growth of fish.

Aquaculture production of olive flounder Paralichthys olivaceus, required low dietary energy level due to ecological characteristics like less movement because 0 : bottom-dwelling fish (Lee et al., 2000a) is one of the highest among the commercially important aquaculture fish in Korea. Several studies on dietary nutrient requirements and optimum feeding frequency for flounder have been reported (Lee et al., 1997; Lee et al., 2000a, b). The objective of this study was to investigate compensatory growth of juvenila olive flounder and determine possible duration of feed deprivation in flounder recovering from starvation to achieve compensatory growth in the spring.

\section{Materials and Methods}

\section{Preparation of the experimental fish}

Juvenile olive flounder were purchased from a private flounder farm and transferred into Uljin Marine Hatchery, Kyungbook, Korea. Twenty juveniles fish (Mean weight \pm S.D.: $53.9 \pm 0.24 \mathrm{~g}$ ) were stocked into the fifteen of $200 \mathrm{~L}$ circular flowthrough tanks (water volume: $160 \mathrm{~L}$ ) and water source was the sand-filtered natural seawater. Fish were acclimated for a week before the initiation of the experiment. During the acclimation period, flounder were fed the commercial sinking flounder feed (Jeilfeed Co., Korea) containing $52.0 \%$ protein and $7.0 \%$ lipid twice daily at $3 \%$ of body weight of fish.

\section{Conditions of the feeding trial}

Based on Lee et al. (2000b)'s study, juvenile flounder were fed the same commercial sinking feed to appare-at satiation twice daily at 09:30 and 17:00 throughout the feeding trial. Fish were fed for 6 days a week. Water flow rate in each tank was 15 $\mathrm{L} / \mathrm{min}$ and photoperiod followed natural condition throughout the feeding trial. Since the feeding trial performec during the spring, mean water temperature ranged from 10.5 to $17.5^{\circ} \mathrm{C}$ (Mean \pm S.D.: $15.0 \pm$ $\left.1.57^{\circ} \mathrm{C}\right)$. Uneaten feeds were siphon-removed after every mea 1 from all tanks and deducted from total feed fed.

\section{Experimental design}

Five treatments of fish with 3 replicates were prepared for this study. Fish in the control group (C) was fed to satiation twice daily throughout the feeding trial. Fish in the S1, S2, S3 and S4 experienced 1, 2, 3 and 4 weeks of starvation, respectively, before being fed to satiation twice daily during the remainder of the experiment. The experiment lasted for 8 weeks. At the end of the feeding trial, fish were collectively harvested and totally weighed.

\section{Chemical analysis}

Five randomly chosen fish at the beginning and 3 fish from each tank at the end of the feeding trial were sacrificed for proximate analysis based on standard method (AOAC, 1990). Also hepasomatic index (HSI $=$ Liver weight $\times 100 /$ fish weight $)$ and condition factor $\left(\mathrm{CF}=\right.$ Fish weight/total length $\left.{ }^{3}\right)$ of 10 fish at the beginning and 3 fish from each tank at the end of the feeding trial were measured. After measuring HSI, liver and body of fish were separately used for proximate analysis.

\section{Statistical analysis}

One-way ANOVA test was applied to test the significance of treatments. And if the significance was observed, Duncan's multiple range test (Duncan, 1955) was applied to detect the difference among treatments by using SAS program version 6.12 (SAS Institute, Inc., Cary, North Carolina, USA).

\section{Results and Discussion}

Survival, weight gain and specific growth rate (SGR) of olive flounder are given in Table 1. Survival of flounder was not significantly $(P>0.05)$ different among treatments, but lowest for fish in S4 fed to satiation for 4 weeks after 4 weeks starvation. Similarly, mortality of fish was not different when an initial weight of $4.3 \mathrm{~g}$ hybrid tilapia was daily fed for 8 weeks or refed after 1,2 and 4 weeks starved (Wang et al., 2000), or when the initial weight of $6.6 \mathrm{~g}$ gibel carp was daily fed for 8 weeks or refed after 1 and 2 weeks starved (Xie et al., 2001). However, mortality of sockeye salmon fry with up to 2 weeks feed deprivation achieved less than $7 \%$ and sharply increased between 3 to 5 weeks feed deprivation and ranged from 42 to $99 \%$ during 12 
Table 1. Survival, weight gain and specific growth rate (SGR) in juvenile flounder fed daily for 8 weeks (C), 7 weeks after 1 week starvation (S1), 6 weeks after 2 weeks starvation (S2), 5 weeks after 3 weeks starvation (S3) and 4 weeks after 4 weeks starvation (S4)

\begin{tabular}{cccccc}
\hline Treatments & $\begin{array}{c}\text { Initial weight } \\
(\mathrm{g} / \text { fish })\end{array}$ & $\begin{array}{c}\text { Final weight } \\
(\mathrm{g} / \text { fish) }\end{array}$ & $\begin{array}{c}\text { Survival } \\
(\%)\end{array}$ & $\begin{array}{c}\text { Weight gain } \\
(\mathrm{g} / \text { fish })\end{array}$ & SGR $^{2}$ \\
\hline C & $53.8 \pm 0.28$ & $78.0 \pm 4.30$ & $96.7 \pm 3.33 \mathrm{n} . \mathrm{s}$. & $24.2 \pm 4.19^{\mathrm{ab}}$ & $0.77 \pm 0.112^{\mathrm{b}}$ \\
S1 & $54.0 \pm 0.27$ & $79.0 \pm 4.65$ & $95.0 \pm 5.00$ & $25.1 \pm 4.58^{\mathrm{ab}}$ & $0.90 \pm 0.137^{\mathrm{ab}}$ \\
S2 & $53.9 \pm 0.28$ & $84.0 \pm 1.49$ & $97.5 \pm 2.50$ & $30.2 \pm 1.64^{\mathrm{a}}$ & $1.24 \pm 0.057^{\mathrm{a}}$ \\
S3 & $53.7 \pm 0.34$ & $72.5 \pm 2.07$ & $95.0 \pm 2.89$ & $18.8 \pm 2.27^{\text {bc }}$ & $1.00 \pm 0.103^{\mathrm{ab}}$ \\
S4 & $53.9 \pm 0.20$ & $65.9 \pm 1.06$ & $86.7 \pm 4.41$ & $11.9 \pm 1.09^{\mathrm{c}}$ & $0.83 \pm 0.070^{\mathrm{b}}$ \\
\hline
\end{tabular}

${ }^{1}$ One tank in $\mathrm{S} 2$ was excluded due to infection of disease.

${ }^{2} \mathrm{SGR}=$ ( $\mathrm{Ln}$ final weight of fish-Ln initial weight of fish)/duration of days of feeding.

Values (Mean \pm SE) in the same column sharing a common superscript are not significantly different $(\mathrm{P}<0.05)$.

week feeding trial (Bilton and Robins, 1973).

Although one tank in S2 were excluded due to infection of disease, weight gain of olive flounder in S2 was significantly $(P<0.05)$ higher than that of fish in $\mathrm{S} 3$ or $\mathrm{S} 4$, but not significantly $(\mathrm{P}>0.05)$ different from that of fish in $\mathrm{C}$ or S1. The poorest weight gain was observed in S4. This indicated that juvenile flounder had limited ability to recover from starvation and achieved compensatory growth when properly refed. Similarly, gibel carp achieved compensatory growth up to 2 weeks feed deprivation, but not for 4 weeks feed deprivation (Qian et al., 2000; Xie et al., 2001). Paul et al. (1995) reported that growth in Alaska yellowfin sole Pleuronectes asper fed for 10 weeks after 2 weeks starvation was similar to that of fish fed daily for 12 weeks. However, compensatory growth of common carp Cyprinus carpio following feed restriction was not observed (Schwarz et al., 1985). Fast growth in olive flounder fed daily to satiation after 1 2 weeks starvation to catch up growth of fish fed daily to satiation for 8 weeks in this study might be associated with an increase in water temperature at the point of being fed. This study was performed between May and June when water temperature increased. Growth of juvenile hybrid tilapia fed for 7 weeks after starved for 1 week was similar to that of fish fed daily for 8 weeks, but better than that of fish fed for 4 and 6 weeks after starved for 4 weeks and 2 weeks, respectively (Wang et al., 2000). Since hybrid tilapia was reared at between 23.8 to $27.0^{\circ} \mathrm{C}$ and its metabolic rate was relatively faster than that of olive flounder in this study, possible duration of feed deprivation for tilapia to catch up growth of fish in control (daily fed) could be shorter than that for flounder. This difference may be due to difference in fish species, water temperature, fish age, feed allowance or duration of the experiment.

Zhu et al. (2001) reported that the omnivorous minnow Phoximus phoximus fully compensated for 1 and 2 weeks of starvation, however, carnivorous stickleback Gasterosteus aculeatus starved for 2 weeks did not achieve full compensation when both fish experienced 1 or 2 weeks of starvation before being fed to satiation. Dobson and Holmes (1984) showed that growth of rainbow trout ( 9 months old) fed 3 weeks after 3 weeks starved was equivalent to or greater than that of fish fed daily for 6 weeks at the ratio of $5 \%$ body weight of fish. Growth of red porgy Pagrus pagrus fed daily during the remainder of the experiment after 1,2 and 4 weeks of feed deprived was similar to that of fish fed daily for 13 weeks and feed consumption was similar among fish groups due to hyperphagy (Rueda et al., 1998). However, growth and weight gain of salmon fry fed daily for 12 weeks was significantly higher than those of all fry fed after any period of starvation (Bilton and Robins, 1973). Gaylord and Gatlin (2000) showed that growth of fingerling channel catfish fed daily during the first 4 weeks after 4 weeks starvation was not as good as that of fish fed daily, but as good as after 8 weeks of refeeding. Most marked compensatory growth was observed in rainbow trout and turbot fed the diet after the least feed ratio was given (Jobling and Koskela, 1996; Saether and Jobling, 1999).

In this study, the poorest SGR was observed in flounder fed daily for 8 weeks in the control. Wang et al. (2000) proved that SGR for hybrid tilapia improved proportional to duration of starvation and 
SGR in f.sh experienced any period of starvation were higher than that in fish fed daily for 8 weeks. Similarly, improved SGR was observed in fish fed after feed restriction (Jobling and Koskela, 1996; Damsgaar 1 and Dill, 1998; Saether and Jobling, 1999; Gray noth and Taylor, 2000; Zhu et al., 2001).

Feed in ake (g/fish), feed efficiency ratio (FER), protein elficiency ratio (PER), protein retention (PR), hepatosomatic index (HSI) and condition factor (CF) in olive flounder are presented in Table 2. Feed intake was proportional to duration of days of feeding except for flounder in S2 fed to satiation for 6 weeks after 2 weeks starvation, but not significantly $(\mathrm{P}>0.05)$ different among $\mathrm{C}, \mathrm{S} 1$ or $\mathrm{S} 2$. And feed intake for fish in S4 was lowest. FER and PER for fish in $S 2$ were significantly $(P<0.05)$ higher then for fish in $\mathrm{C}$, but not significantly (P> 0.05 ) different from those for fish in S1, S3 or S4. However, no significant $(P>0.05)$ difference in $P R$ was observed among fish groups. Evidence of compensatory growth of flounder in S2 in this study was acconpanied by improved SGR, FER and PER. Cornpensatory growth followed by improved FER was observed in other fish (Jobling et al., 1994; Qia: et al., 2000; Gaylord and Gatlin, 2001). Qian et 11. (2000) concluded that compensatory growth in gibel carp was accompanied by improved FER, protein and energy retention, but such improvement wils not obtained by a higher digestibility or reduced swimming activity. However, Wang et al. (2000) mentioned that improved FER was not ob- served in hybrid tilapia achieving compensatory growth after starvation.

HSI and CF for flounder in S1, S3 and S4 were not significantly $(P>0.05)$ different from those for olive flounder in $\mathrm{C}$, but significantly $(\mathrm{P}<0.05)$ lower than S2 except for CF in S1 at the end of the experiment in this study. Gaylord and Gatlin (2000) showed that HSI and CF of fingerling channel catfish decreased rapidly during the fasting period and increased rapidly during subsequent refeeding, and almost same level as control. HSI in red porgy Pagrus pagrus decreased with duration of starvation, but was not different after refeeding (Rueda et al., 1998).

Proximate composition of the whole body of olive flounder, except for liver at the end of the experiment is shown in Table 3. Moisture, protein, lipid and ash content of the body of fish was not significantly $(P>0.05)$ different among treatments. Similarly, protein, lipid and ash content of rainbow trout and red porgy was not affected by duration of starvation after refeeding (Quinton and Blake, 1990; Rueda et al., 1998). Also, protein and lipid content of muscle and liver in channel catfish was not affected by feeding regime (Gibson and Gatlin, 2001).

In conclusion, compensatory growth was obtained in juvenile flounder properly refed after starved up to 2 weeks in the spring. Improved SGR, FER and PER supported compensatory growth of flounder, and no difference in proximate composition of the

Table 2. Feed intake (g/fish), feed efficiency ratio (FER), protein efficiency ratio (PER), protein retention (PR), hepatosomatic index (HSI) and condition factor (CF) in flounder with various feeding regimes at the end of feeding trial ${ }^{1}$

\begin{tabular}{ccccccc}
\hline Treatments & Feed intake & FER & PER & PR & CF & HSI \\
\hline C & $26.2 \pm 1.87^{\mathrm{a}}$ & $0.89 \pm 0.085^{\mathrm{b}}$ & $1.72 \pm 0.162^{\mathrm{b}}$ & $2.5 \pm 0.98 \mathrm{n} . \mathrm{s}$. & $1,470.2 \pm 6.48^{\mathrm{b}}$ & $1.33 \pm 0.19^{\mathrm{b}}$ \\
S1 & $23.9 \pm 0.93^{\mathrm{ab}}$ & $1.03 \pm 0.110^{\mathrm{ab}}$ & $1.99 \pm 0.211^{\mathrm{ab}}$ & $1.7 \pm 0.55$ & $1,600.1 \pm 6.42^{\mathrm{ab}}$ & $1.24 \pm 0.17^{\mathrm{b}}$ \\
S2 & $24.7 \pm 0.08^{\mathrm{ab}}$ & $1.22 \pm 0.062^{\mathrm{a}}$ & $2.35 \pm 0.098^{\mathrm{a}}$ & $3.3 \pm 0.43$ & $1,713.8 \pm 7.17^{\mathrm{a}}$ & $1.74 \pm 0.26^{\mathrm{a}}$ \\
S3 & $19.5 \pm 1.48^{\mathrm{b}}$ & $0.97 \pm 0.046^{\mathrm{ab}}$ & $1.87 \pm 0.089^{\mathrm{ab}}$ & $4.7 \pm 1.31$ & $1,400.0 \pm 5.29^{\mathrm{b}}$ & $1.36 \pm 0.17^{\mathrm{b}}$ \\
S4 & $12.3 \pm 1.15^{\mathrm{c}}$ & $0.97 \pm 0.068^{\mathrm{ab}}$ & $1.87 \pm 0.131^{\mathrm{b}}$ & $4.1 \pm 1.69$ & $1,450.4 \pm 4.73^{\mathrm{b}}$ & $1.40 \pm 0.17^{\mathrm{b}}$ \\
\hline
\end{tabular}

${ }^{1}$ Values (Mean $\pm \mathrm{SE}$ ) in the same column sharing a common superscript are not significantly different $(\mathrm{P}<0 .(5)$.

Hepatcsomatic index (HSI) and condition factor (CF) of flounder at the beginning of the feeding trial were $146 \pm 0.27$ and $1,091.0 \pm 6.80$, respectively.

Feed efficiency ratio (FER) $=$ Weight gain of fish/feed fed.

Proteir. efficiency ratio (PER) $=$ Weight gain of fish/protein fed.

Proteir. retention $(P R)=$ Protein gain $\times 100 /$ protein fed.

Condition factor $(\mathrm{CF})=$ Fish weight $(\mathrm{g}) /$ total length $(\mathrm{cm})^{3}$.

Hepatosomatic index $(\mathrm{HSI})=$ Liver weight $\times 100 /$ fish weight. 
Table 3. Proximate composition ( $\%$ ) of the body of flounder except for liver with various feeding regimes at the end of the feeding trial

\begin{tabular}{cllll}
\hline $\begin{array}{c}\text { Treat } \\
\text { ments }\end{array}$ & \multicolumn{1}{c}{ Moisture } & \multicolumn{1}{c}{ Protein } & \multicolumn{1}{c}{ Lipid } & \multicolumn{1}{c}{ Ash } \\
\hline C & $74.1 \pm 1.18$ n.s. & $18.6 \pm 0.72$ n.s. & $2.3 \pm 0.24$ n.s. & $4.0 \pm 0.04$ n.s. \\
S1 & $75.2 \pm 0.82$ & $18.1 \pm 0.42$ & $2.4 \pm 0.88$ & $3.7 \pm 0.15$ \\
S2 & $74.7 \pm 1.25$ & $18.4 \pm 0.56$ & $1.8 \pm 0.68$ & $4.0 \pm 0.10$ \\
S3 & $74.3 \pm 0.30$ & $18.9 \pm 0.52$ & $2.5 \pm 0.53$ & $3.9 \pm 0.36$ \\
S4 & $76.0 \pm 1.35$ & $18.3 \pm 0.70$ & $1.9 \pm 0.69$ & $4.0 \pm 0.06$ \\
\hline
\end{tabular}

Moisture, protein, lipid, and ash content of the initial fish were $75.5 \pm 0.22,17.3 \pm 0.39,2.1 \pm 0.03$ and $4.2 \pm 0.28$, respectively.

Values (Mean $\pm \mathrm{SE}$ ) in the same column sharing a common superscript are not significantly different $(P<0.05)$.

whole body of fish was observed at the end of the experiment.

\section{References}

AOAC (Association of Official Analytical Chemists). 1990. Official Methods of Analysis. 15th edition. Association of Official Analytical Chemists. Arlington, Virginia. 1298pp.

Bilton, H.T. and G.L. Robins. 1973. The effects of starvation and subsequent feeding on survival and growth of fulton channel sockeye salmon fry. J. Fish. Res. Board Can., 30, $1 \sim 5$.

Damsgaard, B. and L.M. Dill. 1998. Risk-taking behavior in weight-compensating coho salmon, Oncorhynchus kisutch. Behav. Ecol., 9, 26 32.

Dobson, S.H. and R.M. Holmes. 1984. Compensatory growth in the rainbow trout, Salmo gairdneri Richardson. J. Fish Biol., 25, 649 656 .

Duncan, D.B. 1955. Multiple range and multiple F tests. Biometrics $11,1 \sim 42$.

Gaylord, T.G. and D.M. Gatlin. 2000. Assessment of compensatory growth in channel catfish Ictalurus punctatus $R$. and associated changes in body condition indices. $J$. World Aqua. Soc., 31, 326 336.

Gaylord, T.G. and D.M. Gatlin. 2001. Dietary protein and energy modifications to maximize compensatory growth of channel catfish (Ictalurus punctatus). Aquaculture 194, 337 348 .

Graynoth, E. and M.J. Taylor. 2000. Influence of different ratios and water temperatures on the growth rates of shortfinned eels and longfinned eels. J. Fish Biol., 57, $681 \sim 699$.

Jobling, M., O.H. Meloy, J. Dos Santos and B. Christiansen. 1994. The compensatory growth response of the Atlantic cod: effects of nutritional history. Aquac. Int., 2, 75 90.
Jobling, M. and J. Koskela. 1996. Interindividual variations in feeding and growth in rainbow trout during restricted feeding and in a subsequent period of compensatory growth. J. Fish Biol., 49, 658 667.

Lee, S.M., C.H. Seo and Y.S. Cho. 1999. Growth of the juvenile olive flounder (Paralichthys olivaceus) fed the diets at different feeding frequencies. J. Korean Fish. Soc., 32, $18 \sim 21$.

Lee, S.M., S.H. Cho and K.D. Kim. 2000a. Effects of dietary protein and energy levels on growth and body composition of juvenile flounder (Paralichthys olivaceus). J. World Aqua. Soc., 31, 306 315.

Lee, S.M., S.H. Cho and D. Kim. 2000b. Effects of feeding frequency and dietary energy level on growth and body composition of juvenile olive flounder (Paralichthys olivaceus). Aqua. Res., 12, 917 923.

Miglavs, I. and M. Jobling. 1989. Effects of feeding regime on food consumption, growth rates and tissue nucleic acids in juvenile Arctic charr, Salvelinus alpinus, with particular respect to compensatory growth. J. Fish Biol., 34, 947 957.

Paul, A.J., J.M. Paul and R.L. Smith. 1995. Compensatory growth in Alaska yellowfin sole, Pleuronectes asper, following food deprivation. J. Fish Biol., 46, 442 448.

Qian, X., Y. Cui, B. Xiong and Y. Yang. 2000. Compensatory growth, feed utilization and activity in gibel carp, following feed deprivation. J. Fish Biol., 56, 228 232.

Quinton, J.C. and R.W. Blake. 1990. The effect of feed cycling and ration level on the compensatory growth response in rainbow trout, Oncorhynchus mykiss. J. Fish Biol., 37, 33 41 .

Rueda, F.M., F.J. Martinez, S. Zamora, M. Kentouri and P. Divanach. 1998. Effect of fasting and refeeding on growth and body composition of red porgy, Pagrus pagrus L. Aqua. Res., 29, 447 $\sim 452$.

Schwarz, FJ., J. Plank and M. Kirchgessner. 1985. Effects of protein or energy restriction with subsequent realimentation on performance parameters of carp (Cyprinus carpio L.). Aquaculture 48, 23 33 .

Saether, B.S. and M. Jobling. 1999. The effects of ration level on feed intake and growth, and compensatory growth after restricted feeding, in turbot Scophthalmus maximus L. Aqua. Res., 30, 647 653.

Wang, Y., Y. Cui, Y. Yang and F. Cai. 2000. Compensatory growth in hybrid tilapia, Oreochromis mossambicus $X$ O. niloticus, reared in seawater. Aquaculture, 189, 101 108.

Xie, S., X. Xhu, Y. Cui, R.J. Wootton, W. Lei and Y. Yang. 2001. Compensatory growth $\mathrm{n}$ the gibel carp following feed deprivation: temporal patterns in growth, nutrient deposition, feed intake and body composition. J. Fish Biol., 8, 999 1009.

Zhu, X., Y. Cui, M. Ali and R.J. Wootton. 2001. Comparison of compensatory growth responses of juvenile threespined stickleback and minnow following similar food deprivation protocols. J. Fish Biol., 58, 1149 1165 . 